\title{
EXPERIENCE WITH ONE AND A HALF VENTRICLE REPAIR
}

Christian Kreutzer, MD ${ }^{\mathrm{a} *}$

Rita de C. Mayorquim, $\mathrm{MD}^{\mathrm{c}}$

Guillermo O. A. Kreutzer, MD ${ }^{\mathrm{a}, \mathrm{c}}$

Willy Conejeros, $\mathrm{MD}^{\mathrm{a}}$

Maria Ines Roman, $\mathrm{MD}^{\mathrm{b}}$

Haydee Vazquez, MD $^{\mathrm{b}}$

Andres J. Schlichter, MD ${ }^{\mathrm{a}, \mathrm{c}}$

Eduardo A. Kreutzer, MD $^{\mathrm{b}}$
Objective: This article presents a 10-year experience with one and a half ventricle repair for right ventricular hypoplasia or dysfunction. Methods: From November 1986 to December 1996, 30 patients (mean age $6.7 \pm 8.5$ years, range 4 months-40 years) with functionally abnormal right ventricles underwent a bidirectional Glenn shunt as part of the repair. Diagnoses included pulmonary atresia with intact ventricular septum (n $=15)$, Ebstein anomaly $(n=5)$, levotransposition of the great arteries $(n$ $=3$, pulmonary stenosis with right ventricular hypoplasia $(n=2)$, tetralogy of Fallot $(n=3)$, dextrotransposition of the great arteries $(n=$ l), and Uhl anomaly $(n=1)$. Concomitantly performed cardiac procedures included atrial septal defect closure $(n=27)$, fenestration of the atrial septum $(n=2)$, right ventricular cavity augmentation $(n=8)$, right ventricular outflow tract enlargement $(n=6)$, transannular patch $(n=$ 13), modified Blalock-Taussig shunt closure $(n=16)$, tricuspid replacement $(n=3)$, tricuspid repair $(n=2)$, Rastelli procedure $(n=3)$, tricuspid commissurotomy $(n=2)$, and double switch $(n=1)$. Results: There were 2 early deaths $(6.6 \%)$ and 1 late death. Mean early postoperative superior vena caval pressure was $14.12 \pm 3.55 \mathrm{~mm} \mathrm{Hg}$ and mean right atrial pressure was $10.3 \pm 5.16 \mathrm{~mm} \mathbf{H g}$. Early oxygen saturation in the operating room with an inspired oxygen fraction of 1 was $97.2 \pm 2.5$; oxygen saturation was $92.3 \pm 4.8$ on room air at discharge. Mean oxygen saturations were $93.6 \% \pm 3.6 \%$ at 1 year of follow-up $(P=.10)$ and 93.5\% $\pm 4.1 \%$ at 5 years $(P=.12)$. Overall survival was $90 \%$ at 5 years, and 21 patients $(77 \%)$ were in New York Heart Association class I, 5 $(\mathbf{1 8 \%})$ were in class II, and $1(2.7 \%)$ was in class III. Conclusion: This procedure provides a valid alternative for correction of right ventricle hypoplasia or dysfunction. Early and intermediate follow-up results compare favorably with those of the Fontan procedure, but long-term follow-up is needed. (J Thorac Cardiovasc Surg 1999;117:662-8)
$\mathrm{T}$ he therapeutic goal in the management of lesions that include right ventricular hypoplasia or dysfunction is the establishment of a pulmonary/systemic ratio of 1 without overloading the systemic ventricle. Since the original contributions of Billingsly and coworkers ${ }^{1}$

From the Divisions of Cardiovascular Surgery ${ }^{\mathrm{a}}$ and Cardiology, ${ }^{\mathrm{b}}$ Ricardo Gutierrez Children's Hospital, and Cardiovascular Surgery, Bazterrica Clinic, ${ }^{\mathrm{c}}$ Buenos Aires, Argentina.

Received for publication July 2, 1998; revisions requested Aug 24, 1998; revisions received Sept 11, 1998; accepted for publication Oct 15,1998 .

Address for reprints: Christian Kreutzer, MD, Children's Hospital, Department of Cardiovascular Surgery, 300 Longwood Ave, Boston, MA 02115.

*The American Association for Thoracic Surgery Evarts A. Graham Fellow 1998/1999.

Copyright (C) 1999 by Mosby, Inc.

$0022-5223 / 99 \$ 8.00+0 \quad \mathbf{1 2 / 1 / 9 5 3 0 1}$ to the one and a half ventricle concept in patients with hypoplastic right ventricle, the indications for this type of repair have expanded to cover a variety of anomalies that feature a functionally abnormal right ventricle that would not be able to cope with the entire pulmonary circulation. ${ }^{2}$ For such anomalies 3 classic approaches had been followed: palliative procedures such as systemic-pulmonary artery or Glenn shunts, biventricular repair with fenestration of the atrial septum, and Fontan-type procedures.

During 27 years of experience with total bypass of the venous ventricle (Fontan procedure) at our institution, ${ }^{3}$ the initial optimism for this type of procedure declined with increasing length of follow-up. Meanwhile the bidirectional Glenn shunt emerged, with good results. ${ }^{4}$ The combination of a bidirectional Glenn shunt with an intracardiac correction of the existing malformations 
offers advantages with respect to traditional approaches to these complex anomalies, such as decreased preload of the abnormal right ventricle and right atrium, lower central venous pressure, no overloading of the systemic ventricle, and less likelihood of pulmonary arteriovenous malformations because lungs are perfused with blood that includes what has been termed the hepatic factor. ${ }^{5}$ This report presents a 10-year experience with one and a half ventricle repair in patients whose right ventricular hypoplasia or dysfunction precluded biventricular repair.

\section{Methods}

Study population. From November 1986 to December 1996, 30 patients at the Ricardo Gutierrez Children's Hospital and Bazterrica Clinic of Buenos Aires underwent a bidirectional Glenn shunt and an additional procedure to incorporate the right ventricle into the pulmonary circulation. There were 13 male and 17 female patients. Diagnoses included pulmonary atresia with intact ventricular septum $(n=15)$, Ebstein anomaly with poor right ventricular function $(n=5)$, levotransposition of the great arteries, ventricular septal defect and pulmonary stenosis or atresia $(n=3)$, pulmonary stenosis and right ventricular hypoplasia $(n=2)$, tetralogy of Fallot with inadequate right ventricle $(n=3)$, dextrotransposition of the great arteries with ventricular septal defect and pulmonary stenosis, $(n=1)$ and Uhl anomaly $(n=1)$. Mean age at operation was $6.7 \pm 8.5$ years, ranging from 4 months to 40 years, and median age was 3.5 years. Mean weight was $16.3 \pm 14.5 \mathrm{~kg}$, ranging from 3.3 to $56 \mathrm{~kg}$, and median weight was $15 \mathrm{~kg}$. Eighteen patients had hypoplastic right ventricles, 9 had dilated right ventricles, and in 3 patients the right ventricular cavity was small after ventricular septal defect closure or baffling. Preliminary palliative procedures included modified Blalock-Taussig shunt $(\mathrm{n}=16)$, pulmonary valvulotomies or valvuloplasties $(\mathrm{n}=15)$, and pulmonary artery banding $(\mathrm{n}=1)$.

\section{Characterization of right ventricle}

Right ventricular size. The sizes of the right ventricle, tricuspid valve, and pulmonary valve were assessed by echocardiography and angiography in the group with right ventricular hypoplasia $(n=18)$. The annular diameters of the tricuspid valve were measured by 2 -dimensional echocardiography and during the operation with the aid of Hegar dilators, and the $Z$ score was calculated. ${ }^{6,7}$ Patients with $Z$ scores lower than -4.5 and with diastolic volumes less than $45 \%$ of predicted of normal were treated as having univentricular hearts.

Right ventricular function. Because this series encompassed a group of anomalies with many different physiologic parameters before the surgical correction, including shunts, ventricular septal defects, severe tricuspid regurgitation, and transposition of the great arteries, right ventricular function could not be assessed with the same method in all cases. Right ventricular function was determined with 2-dimensional Doppler echocardiography (pulmonary artery flow veloci- ty and in the last 2 years of this experience tricuspid excursion and transtricuspid flow as an estimate of diastolic function) and cineangiocardiography (right ventriculography). The diagnosis of right ventricular dysfunction was finally achieved through the analysis of all the available data.

One and a half versus biventricular repair in mild right ventricular hypoplasia. No patient in the group with right ventricular hypoplasia with a $Z$ score greater than -1 and a volume of more than $90 \%$ of predicted normal underwent a one and a half ventricle repair. The decision to perform a one and a half ventricle repair was made after taking into consideration morphologic and functional issues.

Surgical technique. Through a median sternotomy, conventional cardiopulmonary bypass with moderate hypothermia $\left(25^{\circ} \mathrm{C}\right)$ was instituted with the use of a DLP Pacifico cannula (Medtronic, Grand Rapids, Mich) for the superior vena cava (SVC). The aorta was crossclamped, multidose crystalloid cardioplegic solution was used in all cases, and the concomitant cardiac procedure was performed. After release of the aortic crossclamp the SVC was transected, with care taken not to injure the sinus node. Bidirectional Glenn shunt was performed with 6-0 running polypropylene suture and the azygos vein was left open in all cases. Finally, patients were rewarmed and cardiopulmonary bypass was discontinued.

An adjustable fenestration was used in selected cases. The decision to leave the fenestration open was based on postoperative hemodynamics. The presence of a right atrial pressure greater than $15 \mathrm{~mm} \mathrm{Hg}$ was considered an indication for opening the fenestration. A transatrial gradient of more than $10 \mathrm{~mm} \mathrm{Hg}$ was considered an additional indication.

Right pulmonary artery banding. In patients with previous pulmonary valve incompetence or in those who required transannular patches or right ventricle-pulmonary artery conduits as part of their concomitant cardiac repair, a slight banding of the right pulmonary artery between the bidirectional Glenn shunt and its origin was carried out to prevent excessive pulsatility, defined as differential pressure of more than $5 \mathrm{~mm}$ $\mathrm{Hg}$, and to impede SVC flow to the right ventricle (Fig 1).

Postoperative care. All patients left the operating room with a left atrial line, right atrial line, and SVC line. Their values were continuously monitored until stabilization. Early extubation was performed in the operating room if possible or in the cardiac intensive care unit during the first postoperative hours. Mild inotropic support was typically given in the form of dopamine at $5 \mu \mathrm{g} \cdot \mathrm{kg}^{-1} \cdot \mathrm{min}^{-1}$. Nitric oxide was used during the last year of this series but in only 1 case.

Follow-up. All patients underwent clinical evaluations, oxygen saturation measurements, perfusion lung scans, echocardiography, and contrast 2-dimensional echocardiography for detection of pulmonary arteriovenous malformations at 1-year intervals. From January 1996 onward, contrast 2-dimensional echocardiography was used to evaluate the presence of arteriovenous malformations by means of an upper body vein injection of $3 \mathrm{~mL}$ normal saline solution in patients smaller than $20 \mathrm{~kg}$ and $6 \mathrm{~mL}$ in patients larger than $20 \mathrm{~kg} .{ }^{8}$ Two patients underwent cardiac catheterization 1 year after the procedure. Exercise tests (functional capacity for 


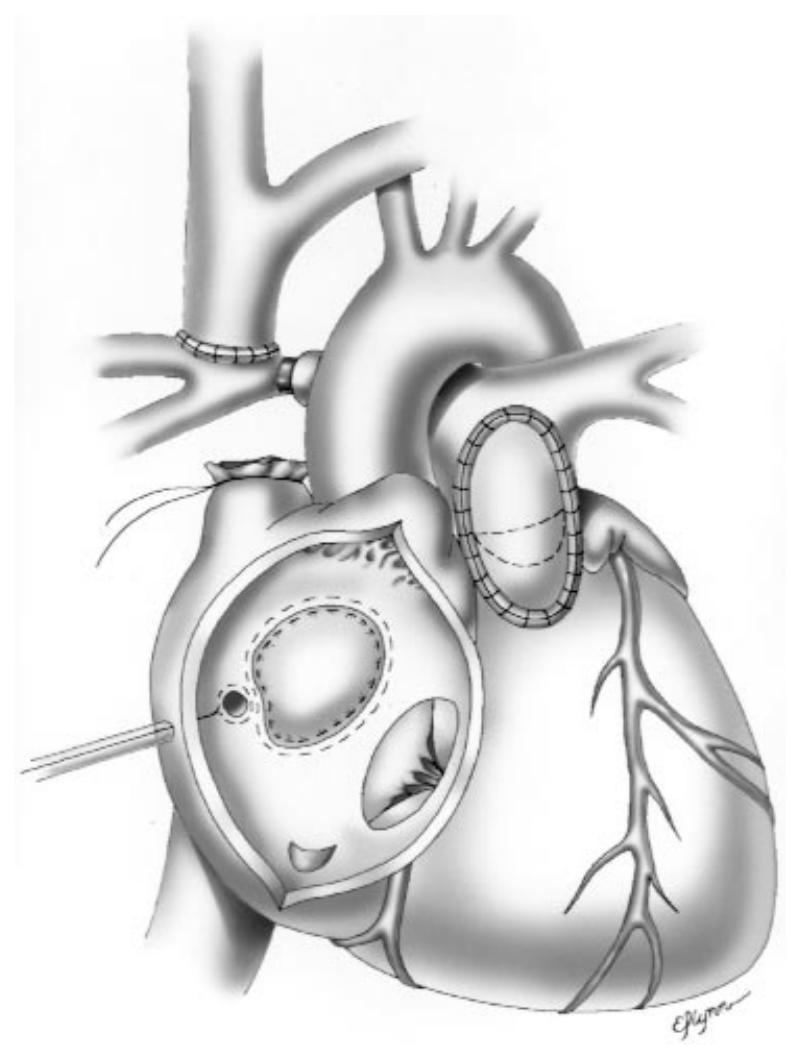

Fig 1. Surgical technique in patients with hypoplastic right ventricle.

age) were performed 2 years after the operation in patients older than 6 years. Follow-up ranged from 1 to 10 years, with a median of 6 years.

Statistics. All values of continuous variables were expressed as mean \pm SD. Comparisons between variables were performed with the Student $t$ test.

\section{Results}

In patients with hypoplastic right ventricles (Fig 1), the anatomic characteristics of the tricuspid and pulmonary valves were evaluated and both anuli were sized. The mean tricuspid $Z$ score for the group with hypoplastic right ventricles $(\mathrm{n}=18)$ was $-3.5 \pm 0.9$ $(-1.2$ to -4.5$)$, and the mean volume was $65 \% \pm 12.8 \%$ (47\%-89\%). In 9 cases the diagnosis of right ventricular dysfunction was made through the analysis of cineangiocardiograms and echocardiograms. Three patients with apparently normal right ventricular size and function underwent the one and a half ventricle repair because the right ventricular cavity was considered small after ventricular septal defect baffling or closure in complex intracardiac repair.
Table I. Concomitant cardiac procedures

\begin{tabular}{lc}
\hline Operation & No. of patients \\
\hline Atrial septal defect closure & 27 \\
Fenestration & 2 \\
Right ventricular cavity augmentation & 8 \\
Right ventricular outflow tract enlargement & 6 \\
Transannular patch & 13 \\
Modified Blalock-Taussig shunt closure & 16 \\
Rastelli procedure & 3 \\
Double switch & 1 \\
Tricuspid replacement & 3 \\
Tricuspid repair & 2 \\
Tricuspid commissurotomy & 2 \\
Right pulmonary artery banding & 20 \\
\hline
\end{tabular}

Surgical procedures. Surgical procedures are listed in Table I. The right ventricular outflow tract was enlarged in 6 patients with autologous pericardial or polyethylene terephthalate fabric (Dacron) hoodshaped patches in an attempt to avoid a transannular patch; however, 13 patients required a pericardial monocuspid valved transannular patch. Augmentation of the right ventricular cavity was performed in 8 patients by means of myotomy and myectomy. In 10 patients the atrial septal defect was closed with double running suture or with a pericardial patch to leave an adjustable $4 \mathrm{~mm}$ fenestration, ${ }^{1}$ which was left open in 2 of them (Fig 1). The right atrium/left atrium ratios in these patients were 4 and 3.5 before the fenestration opening and 1.7 and 1.4 afterward. Two patients underwent tricuspid commissurotomy in the first year of this series.

In patients with Ebstein anomaly the tricuspid valve was carefully evaluated for repair or replacement. Two repairs with Danielson and associates' technique ${ }^{9}$ and 3 replacements were performed.

Three patients with tetralogy of Fallot and inadequate right ventricles were treated in this series. One of them had tricuspid $Z$ score lower than normal and the remaining 2 had dilated right ventricles with dysfunction; all needed a transannular patch as part of their repair and underwent right pulmonary artery banding. In a patient with dextrotransposition of the great arteries who underwent a Rastelli procedure, the size of the right ventricle appeared to be small after ventricular septal defect baffling. Right ventricle-pulmonary artery continuity was established with autologous pericardial valved conduits in 4 patients. ${ }^{10}$ In the patient with Uhl anomaly and pulmonary stenosis, right ventricle free wall plication was performed, a transannular patch was used, and a 4-mm atrial septal fenestration was left open. 
Twenty procedures included banding of the right pulmonary artery. Two classic Glenn shunts were performed early in this series.

Early results. There were 2 early deaths (6.6\%), both of patients with pulmonary atresia with intact ventricular septum in the first 2 years of this series (Table II). The cause of death in both cases was low cardiac output with low left heart filling pressures and high right atrial pressure on postoperative day 1 .

The mean length of stay was $9.2 \pm 8.1$ days, ranging from 5 to 53 days. The mean intensive care unit stay was $3.2 \pm 4.1$ days, ranging from 1 to 22 days. The early postoperative mean SVC pressure was $14.12 \pm 3.55$ $\mathrm{mm} \mathrm{Hg}$, and the mean right atrial pressure was $10.3 \pm$ $5.16 \mathrm{~mm} \mathrm{Hg}$. Mean left atrial pressure was $5.78 \pm 3.1$ $\mathrm{mm} \mathrm{Hg}$. Mean right atrium/left atrium ratio was 1.78 . Early oxygen saturation in the operating room with an inspired oxygen fraction of 1 was $97.2 \% \pm 2.5 \%$. At hospital discharge the oxygen saturation was $92.3 \% \pm$ $4.8 \%$ on room air. One patient with pulmonary atresia with intact ventricular septum who underwent right ventricular cavity enlargement and atrial septal defect closure needed ventilatory support and treatment with nitric oxide for 7 days because of respiratory distress syndrome with high right atrial and SVC pressures.

Reinterventions. There were two reoperations, both tricuspid valve replacements for severe tricuspid regurgitation in the 2 patients with pulmonary atresia with intact ventricular septum who underwent tricuspid commissurotomy as part of the repair. One patient with pulmonary atresia with intact ventricular septum underwent coil occlusion of coronary sinusoids through the right ventricle 1 year after the operation, and his clinical condition improved from New York Heart Association functional class III to class II.

Follow-up. The mean oxygen saturations were $93.6 \% \pm 3.6 \%$ at 1 year of follow-up $(P=.10)$ and $93.5 \% \pm 4.1 \%$ at 5 years $(P=.12)$. Both results were not significantly different from the oxygen saturation values at discharge. The overall survival at 5 years was $90 \%$, with $21(77 \%)$ patients in New York Heart Association functional class I, 5 (18\%) in class II, and $1(2.7 \%)$ in class III. Results of perfusion lung scans and exercise treadmill tests are summarized in Tables III and IV. Poor exercise test results showed a strong correlation with poor right ventricular function, with the patients with pulmonary atresia with intact ventricular septum and Ebstein anomaly showing less satisfactory performance. The 2-dimensional Doppler echocardiograms obtained in the SVC revealed pulsatile flow in $85 \%$ of the patients $(\mathrm{n}=23)$ and no pulsatility in $13 \%(\mathrm{n}=4)$. Contrast 2-dimensional
Table II. Early deaths

\begin{tabular}{lrcc}
\hline & \multicolumn{3}{c}{ Early deaths } \\
\cline { 2 - 5 } Diagnosis & $N$ & No. & $\%$ \\
\hline Pulmonary atresia, intact ventricular septum & 15 & 2 & 12.5 \\
Ebstein anomaly & 5 & 0 & 0 \\
Levotransposition of the great arteries, & 3 & 0 & 0 \\
$\quad$ ventricular septal defect, pulmonary stenosis, & & & \\
$\quad$ pulmonary atresia & & & \\
Dextrotransposition of the great arteries, & 1 & 0 & 0 \\
$\quad$ ventricular septal defect, pulmonary stenosis & 3 & 0 & 0 \\
Tetralogy of Fallot & 2 & 0 & 0 \\
Pulmonary stenosis and right ventricular & & & \\
$\quad$ hypoplasia & 1 & 0 & 0 \\
$\quad$ Uhl anomaly & & & \\
\hline
\end{tabular}

echocardiography showed no pulmonary arteriovenous malformations; however, 2 cases of venovenous collaterals without oximetric impairment were observed. In the 4 patients with autologous pericardial valved conduits, no conduit replacements were required because such conduits had shown a tendency to increase in diameter with time. ${ }^{10}$ The patient with Uhl anomaly died 3 years after the operation of intractable ventricular arrhythmia. One patient with pulmonary atresia with intact ventricular septum who underwent right ventricular cavity enlargement, bidirectional Glenn shunt, and fenestration is currently awaiting a Fontan procedure because of poor right ventricular function, extremely high right atrial pressure, and increased cyanosis from right-to-left shunting through a fenestration of the atrial septum.

\section{Discussion}

In recent years reservations have emerged regarding the Fontan procedure, with reports noting supraventricular arrhythmias, right-sided heart failure, protein-losing enteropathy, ascites, liver dysfunction, right atrial thrombosis with pulmonary embolism, and other complications. ${ }^{11,12} \mathrm{~A}$ fenestrated Fontan procedure still carries significant late morbidity; there are still some concerns with arrhythmias, mild cyanosis, paradoxic emboli, need for anticoagulation, and persistently elevated right atrial pressures. ${ }^{11,13}$ The introduction of new surgical techniques for the Fontan operation, such as the total extracardiac conduit, is expected to produced a better late outcome for this type of circulation.

Since the introduction of the bidirectional Glenn shunt in the early 1980s, this palliative procedure has increased in popularity among cardiac surgeons around the world. In recent years, however, words of caution have emerged regarding the bidirectional Glenn 
Table III. Perfusion lung scan: Percentages of lung perfusion through upper body and lower body injections

\begin{tabular}{llcccc}
\hline & \multicolumn{2}{c}{ Upper body $(\%)$} & & \multicolumn{2}{c}{ Lower body (\%) } \\
\cline { 2 - 3 } Type of Glenn shunt & Right lung & Left lung & & Right lung & Left lung \\
\hline Classic Glenn shunt $(\mathrm{n}=2)$ & 100 & 0 & 0 & 100 \\
Bidirectional Glenn shunt $(\mathrm{n}=5)$ & $65.75 \pm 11.08$ & $34.25 \pm 11.08$ & & $56.75 \pm 7.5$ & $42.75 \pm 7.5$ \\
Bidirectional Glenn shunt with right pulmonary & $88.37 \pm 8.3$ & $11.62 \pm 8.3$ & & $45.1 \pm 14.8$ & $54.9 \pm 14.8$ \\
$\quad$ artery banding $(\mathrm{n}=17)$ & & & & \\
\hline
\end{tabular}

$* P=.001$.

Table IV. Exercise test results $(n=20)$ in mean functional capacity for age between diagnostic groups

\begin{tabular}{lcc}
\hline & \multicolumn{2}{c}{ Functional capacity (\%) } \\
\cline { 2 - 3 } Diagnosis & Mean & Range \\
\hline Pulmonary atresia with & $67.91 \pm 21$ & $45-100$ \\
$\quad$ intact ventricular septum & & \\
Ebstein anomaly & $78.33 \pm 13.12$ & $50-95$ \\
Levotransposition of the great arteries & 85 & $70-95$ \\
Pulmonary stenosis and right & 80 & $75-85$ \\
$\quad$ ventricular hypoplasia & & \\
Dextrotransposition of the great arteries & 87 & \\
Tetralogy of Fallot & 100 & $100-100$ \\
\end{tabular}

All percentages are based on a definition of normal as $100 \%$.

shunt, ${ }^{14,15}$ related to increased cyanosis with age caused by changes in the body configuration, development of venous collaterals, and arteriovenous malformations caused by the absence of a hepatic factor in the pulmonary circulation. ${ }^{5}$

The palliative nature of a complete Fontan procedure and its worrisome long-term results have lead to a search for a surgical option that would incorporate the venous ventricle in the pulmonary circulation, even when its function and structure were such that it would be inadequate to carry a total cardiac output. The concept of the one and a half ventricle physiologic construction can be expanded to any lesion with inadequate right ventricles, from right ventricular hypoplasia to right ventricular cardiomyopathy, with the advantages of unloading the right atrium and ventricle, restoring a pulmonary/systemic circulation ratio of 1 , including flow from the hepatic veins in the pulmonary circulation, and possibly serving as a bridge toward the Fontan procedure in cases of progressive severe right ventricular failure.

Biventricular repair is associated with significant early morbidity and mortality among patients with inadequate right ventricles. ${ }^{16}$ Thus the possibility of adding a bidirectional Glenn shunt to the repair offers the considerable advantage of lowering the right ven- tricle preload in the immediate postoperative period. Moreover, the bidirectional Glenn shunt easily can be performed if the postbypass hemodynamic status is not satisfactory. The indications for this procedure in right ventricular hypoplasia are not yet completely clear. We limited the use of this procedure to patients with a tricuspid valve of a $Z$ score of -4.5 , but others ${ }^{17-19}$ expanded the limit down to -5 or -6 and performed this type of procedure on patients with ventricles with a mean volume of $48.4 \%$ of predicted of normal, although the mean $Z$ scores in those series are similar to the mean $Z$ score in this study. In our experience selection of the suitable right ventricle in pulmonary atresia with intact ventricular septum should be focused not only on volumes and $Z$ scores but also on the right ventricular function, right ventricular compliance, and pulmonary vascular resistance.

Excessive pulsatility in the SVC associated with pulmonary insufficiency was the main indication for right pulmonary artery banding. Likewise, Gentles and coworkers $^{20}$ from Boston Children's Hospital performed ligation of the right pulmonary artery proximal to the Glenn shunt in 5 of 8 patients. Right pulmonary artery banding would decrease the pulsatility associated with pulmonary regurgitation as a result of right ventricular outflow tract reconstructions. Pericardial monocuspid and bicuspid valves have shown good function in the first months after the operation but complete failure during late follow-up. ${ }^{10,21}$ The presence of free pulmonary regurgitation would theoretically compromise even further the functional efficiency of an already abnormal right ventricle. Furthermore, free pulmonary regurgitation can lead to a circulation in which the blood from the SVC flows to the right ventricle. In that case the one and a half ventricle repair loses part of its physiologic rationale, because the right ventricular preload is no longer reduced. Right pulmonary artery banding would therefore prevent blood flow from the SVC from entering the right ventricle, directing it to the right pulmonary artery. In addition, excessive pulsatility associated with free pulmonary 
regurgitation has been described as resulting in an aneurysm formation of the SVC, so the use of a right pulmonary artery banding would avoid such a complication. ${ }^{2,17}$ In one of the reported cases with this complication, a patient needed the implantation of a pulmonary valve, carrying the unavoidable consequences of anticoagulation and lack of growth with time. However, further follow-up is needed to evaluate the impact of banding the right pulmonary artery, particularly with respect to the development of right-sided pulmonary arteriovenous malformations and effects on right lung development.

Another difficult issue is determination of when to include a fenestration as part of this procedure. We used adjustable fenestrations in 10 patients and had to leave the fenestration open in 2 cases. The 2 patients who died early after the operation of low cardiac output and very low left atrial pressures and high right atrial pressures would theoretically have benefited from an open fenestration. Because nitric oxide may play a significant role in the postoperative management of these patients, such as in the case of a failing postoperative Fontan circulation, the indications for fenestrations could be reduced.

The azygos vein was left open in all patients because that would theoretically carry the advantage of decompressing the SVC or the right atrium in patients with SVC hypertension or severe right ventricular dysfunction, respectively, without oximetric impairment.

In patients with Ebstein anomaly with dilated right atria and right ventricles, the bidirectional Glenn shunt decreases preload and has an impact on arrhythmias and on right ventricular function..$^{22}$ It may also be used as an alternative or a bridge to heart transplantation in patients with severe right ventricular dysfunction.

Another advantage of this approach for the patient with Rastelli-type repairs is that it will prolong the conduit survival by reducing the venous ventricle preload. In levotransposition of the great arteries and dextrotransposition of the great arteries with right atrioventricular valve straddling, the possibility of adding a bidirectional Glenn shunt to the repair should be taken into consideration because right ventricular volume is often decreased with Rastelli-type operations.

The results of the perfusion pulmonary scintigraphy (lung scan) demonstrate an abnormal distribution of pulmonary blood flow, ${ }^{23}$ showing a clear preference for the right lung as in all bidirectional Glenn shunts and total cavopulmonary connections. This was further exacerbated in cases with right pulmonary artery banding. Follow-up is needed to assess the long-term effects of this abnormal distribution on right lung function.
The results of exercise testing 2 years after the operation differed among diagnostic groups. Worse results were observed in patients with pulmonary atresia with intact ventricular septum and Ebstein anomaly. Poor results in exercise tests showed a strong correlation with poor right ventricular function.

Limitations of the study. Because this report encompasses a variety of complex forms of lesions with abnormal right ventricle, both the number of patients and the retrospective, nonrandomized character of the study do not allow meaningful statistical assessment through multivariable analysis. In addition, the small number of patients does not allow determination of which morphologic and functional right ventricular parameters predict a successful one and a half ventricle repair and what role this procedure should play in the treatment of patients with mild right ventricular inadequacy.

Conclusion. The one and a half ventricle repair appears to be a valid alternative to Fontan and biventricular repairs in patients with right ventricular dysfunction or hypoplasia. Early and intermediate followup results compare favorably with those of the Fontan procedure; however, more follow-up is needed to establish the long-term results of this procedure.

\section{Addendum}

From January 1997 to January 1998, another 3 patients successfully underwent one and a half ventricle repair. Two patients with Ebstein anomaly, 16 and 27 years old, who were considered for transplantation underwent a bidirectional Glenn shunt without right pulmonary artery banding and with aggressive tricuspid plasty. An 18-month-old infant with dextrotransposition of the great arteries, ventricular septal defect, and straddling tricuspid valve who had undergone pulmonary artery banding as a neonate underwent an arterial switch operation, ventricular septal defect closure, and bidirectional Glenn shunt without right pulmonary artery banding.

We thank Richard A. Jonas, MD, for constructive criticism of the manuscript.

\section{REFERENCES}

1. Billingsly AM, Laks H, Boyse SW, George B, Santulli T, Williams RG. Definitive repair in patients with pulmonary atresia and intact ventricular septum. J Thorac Cardiovasc Surg 1989; 97:46-54.

2. Van Ardsell GS, Williams WG, Maser CM, Stritenberger KS, Rebeyka IM, Coles JG, Freedom RM. Superior vena cava to pulmonary artery anastomosis: an adjunct to biventricular repair. J Thorac Cardiovasc Surg 1996;112:1143-9.

3. Kreutzer G, Galindez E, Bono H, De Palma C, Laura JP. An operation for the correction of tricuspid atresia. J Thorac Cardiovasc Surg 1973;66:613-21. 
4. Kopf GS, Laks H, Stansel HC, Hellenbrand WE, Kleinman CS, Talner NS. Thirty year follow up of superior vena cava-pulmonary artery (Glenn) shunts. J Thorac Cardiovasc Surg 1990;100:662-71.

5. Marshall B, Duncan BW, Jonas RA. The role of angiogenesis in the development of pulmonary arteriovenous malformations in children after cavopulmonary anastomosis. Cardiol Young 1997;7:370-4.

6. Kirklin JW, Barratt-Boyes BG. Surgical concepts, research methods, and data analysis and use. In: Kirklin JW, Barratt-Boyes BG. Cardiac surgery. 1st ed. New York: John Wiley and Sons; 1986. p. 177-204.

7. Hanley FL, Sade RM, Blackstone EH, Kirklin JW, Freedom RM, Nanda NC. Outcomes in neonatal pulmonary atresia with intact ventricular septum: a multiinstitutional study. J Thorac Cardiovasc Surg 1993;150:406-27.

8. Bernstein HS, Brook MM, Silverman NH, Bristow J. Development of pulmonary arteriovenous fistulae in children after cavopulmonary shunt. Circulation 1995;92:(suppl 11)309-414.

9. Danielson GK, Driscoll DJ, Mair DD, Warnes CA, Oliver WC. Operative treatment of Ebstein's anomaly. J Thorac Cardiovasc Surg 1992;104:1195-202.

10. Schlichter AJ, Kreutzer C, Mayorquim RC, Simon JL, Roman MI, Vazquez H, Kreutzer G. Long term follow up of autologous pericardial valved conduit. Ann Thorac Surg 1996;62:155-60.

11. Driscoll DJ, Offord KP, Feldt RH, Schaff HV, Puga FJ, Danielson GK. Five to fifteen year follow up after the Fontan operation. Circulation 1992;85:469-96.

12. Gentles TL, Mayer JE, Gauvreau K, Newberger JW, Lock JE, Kupferschnid JP, et al. Fontan operation in five hundred consecutive patients: factors influencing early and late outcome. J Thorac Cardiovasc Surg 1997;114:376-91.

13. DuPlessis AJ, Chang AC, Wessell DL, Lock JE, Wernovsky G, Newberger JW, et al. Cerebrovascular accidents following the Fontan operation. Pediatr Neurol 1995;12:230-5.

14. Jonas RA. Indications and timing for the bidirectional Glenn shunt versus the fenestrated Fontan circulation. J Thorac Cardiovasc Surg 1994;108:522-4.
15. Cloutier A, Ash JM, Smallhorn JF. Abnormal distribution of pulmonary blood flow after the Glenn shunt or Fontan procedure: risk of development of arteriovenous fistulae. Circulation 1985; 72:471-9.

16. Delius RE, Rademecker MA, de Leval MR, Elliott MJ, Stark J. Is a high-risk biventricular repair always preferable to conversion to a single ventricle repair? J Thorac Cardiovasc Surg 1996;112: 1561-8.

17. Reddy VM, McElhinney DB, Silverman NH, Marianeschi SM, Hanley FL. Partial biventricular repair for complex congenital heart defects: an intermediate option for complicated anatomy or functionally borderline right complex heart. J Thorac Cardiovasc Surg 1998;116:21-7.

18. Clapp SK, Tantengco MV, Walters HL, Lobdell KW, Hakimi M. Bi-directional cavopulmonary anastomosis with intracardiac repair. Ann Thorac Surg 1997;63:746-50.

19. Muster AJ, Zalles VR, Ilbawi MN, Backer CL, Duffy CE, Mavroudis C. Biventricular repair of hypoplastic right ventricle assisted by pulsatile bidirectional cavopulmonary anastomosis. $\mathbf{J}$ Thorac Cardiovasc Surg 1993;105:112-9.

20. Gentles TL, Keane JF, Jonas RA, Marx GE, Mayer JE Jr. Surgical alternatives to the Fontan procedure incorporating a hypoplastic right ventricle. Circulation 1994;90(Pt 2):1-6.

21. Gundry SR, Razzouk AJ, Boskind JF, Bansal R, Bailey LL. Fate of the pericardial monocusp pulmonary valve for right ventricular outflow tract reconstruction: early function, late failure without obstruction. J Thorac Cardiovasc Surg 1994;107:908-12.

22. Kreutzer GO. Discussion of Hetzer R, Nagdyman N, Ewert P, Weng YG, Meskhisvili VA, Berger F, et al. A modified repair technique for tricuspid incompetence in Ebstein's anomaly. J Thorac Cardiovasc Surg 1998;115:857-68.

23. Kreutzer EA, Quilindro AH, Barber BJ, Batista N, Grippo M, Roman MI, Kreutzer GO. Study of pulmonary perfusion using pulmonary scintigraphy in total or partial bypass of the right ventricle at rest and with exertion [abstract]. J Am Coll Cardiol 1995;25(suppl A):305A. 